\title{
Erector Spinae Plane Block for Ivor Lewis Oesophagectomy: An Opioid-sparing Technique
}

\author{
Seng Zhi Quan ${ }^{1}$ and Wong Wan Yi \\ ${ }^{1}$ Woodlands Health Campus, Department of anaesthesiology \\ ${ }^{2}$ Tan Tock Seng Hospital, Department of anaesthesiology
}

\section{Background}

Ivor Lewis oesophagectomy is a minimally invasive technique which requires abdominal and right thoracic dissection with an intrathoracic anastomosis. Traditionally, the analgesic plan for these surgeries included IV paracetamol and IV opioids via patientcontrolled analgesia (PCA) pumps. IV nsaids/cox-2 inhibitors have also been used occasionally but their use has been limited by concerns of bleeding and nephrotoxicity.

Poorly controlled pain in these patients can lead to respiratory complications, deconditioning secondary to inability to engage with physiotherapy and patient dissatisfaction. High opioid consumption is associated with increased incidence of ileus and more significant nausea and vomiting.

The use of erector spinae plane (ESP) block has been successfully described as an analgesic option for multi-level rib fractures and thoracic surgeries ${ }^{1,2}$. We postulated that ESP can also potentially decrease the reliance on IV opioids for analgesia for Ivor Lewis oesophagectomy.

\section{Case Report}

We describe a case featuring the use of bilateral ESP blocks as an opioid sparing technique for an Ivor Lewis oesophagectomy in a 60-year-old gentleman with known hyperlipidaemia and oesophageal carcinoma.

\section{Anaesthesia}

Bilateral single-shot ESP block was done at T6 pre-operatively and $25 \mathrm{ml}$ boluses of Ropivacaine $0.3 \%$ with adrenaline $1: 400 \mathrm{k}$ were given to each side respectively.

Induction was with IV propofol, lignocaine, fentanyl and atracurium. Anaesthesia was maintained with desflurane and a titrated IV remifentanil infusion (total dose $1.24 \mathrm{mg}$ ).

\section{Surgical duration was $5.5 \mathrm{hrs}$}

\section{Multi-modal analgesia}

IV paracetamol $1 \mathrm{~g}$ and IV morphine $10 \mathrm{mg}$ were given $30 \mathrm{~min}$ to $1 \mathrm{hr}$ prior to extubation.

Post-operatively, he was prescribed IV paracetamol 1g Q6H and PCA fentanyl.

\section{Results}

\begin{tabular}{|c|c|c|c|c|}
\hline & \begin{tabular}{|l} 
VAS \\
(at rest)
\end{tabular} & \begin{tabular}{|l} 
VAS \\
(dynamic)
\end{tabular} & $\begin{array}{l}\text { PCA fentanyl } \\
\text { usage (mog) }\end{array}$ & Documented activity levels \\
\hline POD 1 & 0 & 4 & 260 & Able to take deep breaths and cough \\
\hline POD 2 & 1 & 3 & 300 & $\begin{array}{l}\text { Incentive spirometry } \times 10(500-750 \mathrm{ml}) \text {; Sit over } \\
\text { edge of bed; Sit to stand; Ambulated from bed } \\
\text { to chair }\end{array}$ \\
\hline POD 3 & 1 & 3 & 120 & $\begin{array}{l}\text { Ambulated } 100 \mathrm{~m} \text { (pushing drip stand himself); } \\
\text { Sat out of bed }>50 \% \text { of the day }\end{array}$ \\
\hline POD 4 & 0 & 2 & 20 & Ambulating independently \\
\hline
\end{tabular}

PCA was taken off on POD 4 while he received IV Paracetamol 1g Q6H until POD 7 after which it was converted to PO Paracetamol 1g Q6H/PRN. No opioids were required after POD 4.

\section{Discussion}

Bilateral ESP block can be done as part of a multimodal analgesic plan to avoid excessive opioid usage in Ivor Lewis oesophagectomy. It is a simple and relatively safe block which should be considered in patients especially in whom high dose opioids can be detrimental. However, a possible next step could be to evaluate the efficacy of continuous ESP block in a RCT to determine if there is any real clinical benefit.

\section{References}

1. Kot $P$, Rodriguez $P$, Granell $M$, et al. The erector spinae plane block: a narrative review. Korean $J$ Anesthesiol. 2019;72(3):209-220. doi:10.4097/kja.d.19.00012

2. D. L. Hamilton, B. Manickam, Erector spinae plane block for pain relief in rib fractures, BJA: British Journal of Anaesthesia, Volume 118, Issue 3, March 2017, Pages 474-475 